\title{
Reversible Cerebral Vasoconstriction Syndrome Associated with a Suprarenal Mass
}

\author{
Camila Pantoja-Ruiz', Andrés Ricaurte-Fajardo², \\ María Isabel Ocampo-Navia ${ }^{2}$, Juliana Coral-Casas ${ }^{1}$ \\ ${ }^{1}$ Neuroscience Department, Hospital Universitario San Ignacio, Pontificia \\ Universidad Javeriana, Bogotá, Colombia; \\ ${ }^{2}$ Medical School, Pontificia Universidad Javeriana, Bogotá, Colombia \\ Received November 17, 2019; Accepted May 28, 2020.
}

Key words: Reversible cerebral vasoconstriction syndrome - Headache Cerebral angiography - Tumour

\begin{abstract}
Reversible cerebral vasoconstriction syndrome (RCVS) is characterised by severe thunderclap headaches (with or without the presence of acute neurological symptoms) and segmental vasoconstriction of cerebral arteries that resolves spontaneously in a period of three months. Cases have been described in the literature with producing and non-producing masses of metanephrines. Within these reports, associations with cavernous haemangioma, medulloblastoma, colon cancer, paraganglioma, pheochromocytoma, uterine fibroids, among others were found. However, no association with adrenal masses which do not produce metanephrines was found. In this context, we reported the case of a woman with this type of tumour associated with RCVS which provided a treatment challenge, as well as we reviewed the literature on cases of RCVS associated with masses.
\end{abstract}

Mailing Address: Camila Pantoja-Ruiz, MD., MSc., Neuroscience Department, Hospital Universitario San Ignacio, Pontificia Universidad Javeriana, Cra. 7 \#40-62, 6xth flor, Bogotá 111017, Colombia; e-mail: camila.pantoja13@gmail.com 


\section{Introduction}

Reversible cerebral vasoconstriction syndrome (RCVS), or Call-Fleming syndrome, is characterised by severe thunderclap headaches (with or without the presence of acute neurological symptoms) and segmental vasoconstriction of cerebral arteries that resolves spontaneously in a period of three months (Calabrese et al., 2007; Coral and Roa, 2009; Sattar et al., 2010; Yeh et al., 2010; Ducros, 2012; Seby et al., 2015; Ducros and Wolff, 2016). This clinical-radiological entity is characterised by the clinical heterogeneity given by the transitory deregulation of cerebral vascular tone that gives rise to multiple focal points of vasospasm (Sattar et al., 2010; Hongliang et al., 2011).

RCVS has a peak incidence around the age of 42 and is more common in women than in men (Chen et al., 2010; Ducros et al, 2010; Ducros, 2012). It is usually self-limited and has a low incidence of recurrence (Sattar et al., 2010). The main complications of this syndrome are ischaemic and haemorrhagic strokes (Ducros et al., 2010; Sattar et al., 2010). Moreover, approximately 60\% of the cases are secondary to a probable cause; the most common being the postpartum period or after exposure to vasoactive substances (Sattar et al., 2010; Ducros, 2012). Because of its multifactorial origin, this syndrome represents a diagnostic challenge. Nevertheless, a high diagnostic suspicion is fundamental to achieve timely management.

Cases have been described in the literature with producing and non-producing masses of metanephrines (Mori et al., 2012; Duke and Ullrich, 2018; Katada et al., 2018; Arenas-Beltrán et al., 2019). Within these reports, associations with cavernous haemangioma, medulloblastoma, colon cancer, paraganglioma, pheochromocytoma, uterine fibroids, among others were found (Mori et al., 2012; Duke et al., 2018; Katada et al., 2018; Arenas-Beltrán et al., 2019). However, no association with adrenal masses which do not produce metanephrines was found. In this context, we reported the case of a woman with this type of tumour associated with RCVS which provided a treatment challenge, as well as we reviewed the literature on cases of RCVS associated with masses.

\section{Case report}

A 55-year-old female original from a rural area Colombia, presented with acute onset frontoparietal left headache which the patient described as the sudden most intense pain she has ever felt in her life. Pain was not associated with changing positions and was not relieved by NSAIDs or paracetamol. Associated with the headache, she described left periocular pain, phonophobia, photophobia, tinnitus, nausea and emesis. She also pointed out that she had been presenting at least 5 episodes of this headache per week during the last month. Each episode reached the highest intensity of pain before 1 minute and lasted for around one hour. She experienced the last episode 6 hours prior the consultation, where she additionally referred blurred vision by both eyes. 
She had history of headaches since she was 25 years old with the same localization, however those episodes were much milder, with a much insidious onset and where relieved with NSAIDs or paracetamol. Additionally, she had history of type 2 diabetes, arterial hypertension, intradermic melanocytic nevus and a basocelular carcinoma infiltrating the deep dermis.

At the initial examination, her blood pressure was $160 / 90 \mathrm{~mm} \mathrm{Hg}$ and the rest of the vitals were normal. Visual acuity bilaterally was restricted to light perception, however fundoscopy was normal on both eyes. Additionally, she presented hypoesthesia on the superior right limb and right agraphesthesia. Rest of the exam was normal.

Magnetic resonance imaging (MRI) was performed finding left occipital and parietal hyperintensities which did not restrict on the diffusion and enhanced with the injection of contrast. These were interpreted as haemorrhagic transformations with mild subarachnoid bleeding. Angiography was then performed finding multiple focal and diffuse stenosis on the anterior and posterior circulation with pre-occlusive arteries on the left parietooccipital territory which conditioned delayed flow bilateral occipital lobes. These findings were interpreted as intracranial vasculitis. Therefore, autoimmune panel and lumbar puncture were performed without any abnormal findings. Based on this, a diagnosis of reversible cerebral vasoconstriction syndrome was made and nimodipine $60 \mathrm{mg} 3$ times daily was prescribed.

Despite the treatment, she kept presenting around 3 episodes of headache per day. Transcranial Doppler was negative for vasospasm, however the median cerebral arteries (MCA) were found to have higher resistance index. Because of this and the persistent visual acuity decrease, intraarterial nimodipine application through angiography was prescribed. During this angiography, a worsening of the stenosis on the anterior bilateral circulation was seen. Nimodipine was intraarterially administered (6 $\mathrm{mg}$ on the left hemisphere and $4 \mathrm{mg}$ on the right one) with an improvement of the calibre of both MCAs. On the aetiology studies, an abdominal CT (computed tomography) reported a left suprarenal lesion suggestive of adenoma.

She was asymptomatic after the intra-arterial nimodipine injection. Still, one week after, she refers again thunderclap headache associated with left superior limb weakness and paraesthesias. Because of this, a new therapeutic and angiography was made. Intra-arterial nimodipine was administered $(7 \mathrm{mg}$ on the left hemisphere and $2 \mathrm{mg}$ on the right hemisphere) without a complete reopening of the MCAs, yet the symptoms resolved. The next day, she referred a new thunderclap headache and weakness and paraesthesias on her right superior limb. A fourth angiography was indicated where it was documented opercular and cortical refractory vasospasm on the left MCA (Figure 1). Nimodipine was administrated intraarterially, however an unfavourable evolution was documented with multiple arterial stenosis due to vasoreactivity. Suddenly, she presented disorientation, anterior aphasia, right hemiinattention, weakness on her right inferior limb and right hemisensitve syndrome 


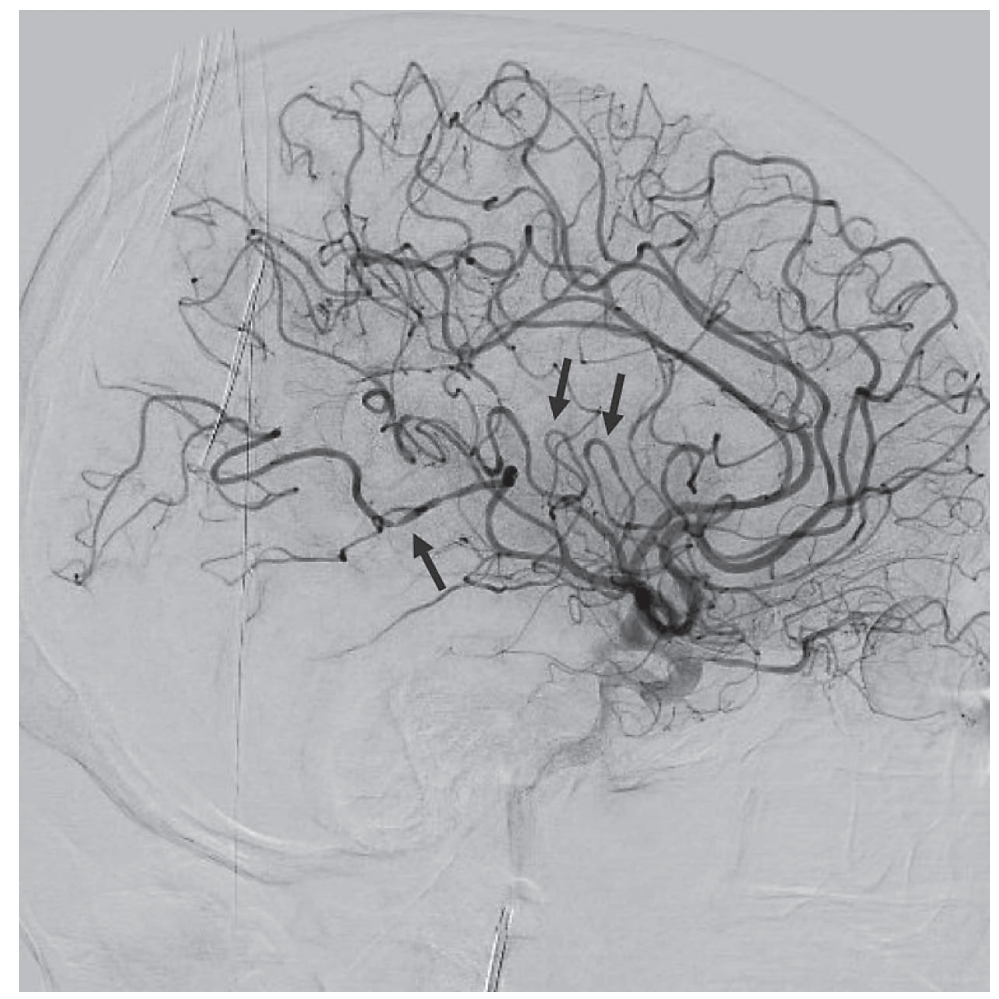

Figure 1 - Angiography showing narrowing of the arteries corresponding to vasospasm.

associated. Arterial stenosis on the left frontal, parietal and parietooccipital territories was documented with unresponsive changes to milrinone and nimodipine. Because of the intense pain she was feeling, $25 \mathrm{mcg}$ of phentanyl and $1 \mathrm{mg}$ of midazolam where administrated and the procedure was stopped. Patient was translated to the intermediate care unit and systemic intraarterial nimodipine was started at a $10 \mathrm{mg} /$ hour dose with resolution of the symptoms.

Two days after, she referred a thunderclap headache with right hemiparesis associated with a thunderclap headache. A sixth angiography was made and this time, the left parietooccipital region was found to be permeable again however the defect at the left parenchimogram was still present. Intraarterial nimodipine was again started with poor angiographical response, yet with good clinical response. By the end of the procedure, systemic arterial pressure decreased, and noradrenaline had to be started. Nimodipine was changed from i.v. administration to the oral form $30 \mathrm{mg}$ every six hours. She was translated to the intensive care unit where she was observed for 5 days with resolution of the headache and with adequate blood pressure control. 
After 10 days of the last thunderclap headache episode and after 7 days of the last angiography, patient was dismissed with a persistent right hemiparesis. Ambulatory PET scan was programmed for the study of the suprarenal lesion and oral nimodipine was continued. She was seen two weeks after being dismissed on the external neurology clinic with no new thunderclap headaches episodes and with partial resolution of the right hemiparesis.

\section{Discussion}

This case illustrates the classic clinical presentation of RCVS. Thunderclap headache is usually the typical symptom with or without neurological focalization and the diagnostic criteria suggested by Calabrese et al. (2007) propose that headache should be associated with diffuse changes in the tone of the cerebral vasculature documented by angiography (De Angelis et al., 2018; Arenas-Beltrán et al., 2019). Because it is usually associated with medical conditions, a classification dividing the aetiology of the syndrome between idiopathic and symptomatic has been purposed (Coral and Roa, 2009). When the RCVS is considered to be symptomatic, pregnancy, neoplasms and systemic diseases should be considered as the primary disease (Coral and Roa, 2009). Because of this relationship, in the clinical setting it becomes necessary to study the patient looking for an underlying aetiology that triggers the multifocal and diffuse cerebral vasospasm (Coral and Roa, 2009). In the presented case, an abdominal CT scan documented a left adrenal lesion suggestive of adenoma as the only abnormal finding.

Adrenal masses are usually found as an incidental finding (incidentalomas) in $0.4 \%$ of all the abdominal CT scans (Herrera et al., 1991). Malignancy is uncommon in patients without a known cancer diagnosis and it can be predicted by the size of the mass, nevertheless, size and imaging characteristics may help determine whether the tumour is or not cancer (Cawood et al., 2009; Nieman, 2010). It has been reported that masses bigger than $4 \mathrm{~cm}$ are associated with adrenocortical carcinoma (Herrera et al., 1991). Concerning the imaging phenotype, a consensus panel reported that a homogenous adrenal mass with a smooth border and an attenuation value $<10 \mathrm{HU}$ on a simple $\mathrm{CT}$ is very likely to be benign, different from pheochromocytomas which usually increase attenuation $>20 \mathrm{HU}$ on the $\mathrm{CT}$ and show increased mass vascularity with delay in the contrast medium washout or the adrenocortical carcinoma which are usually irregular, have usually a diameter greater than $4 \mathrm{~cm}$ and present non homogeneous density due to tumour necrosis or calcifications (Grumbach et al., 2003).

There are some cases describing the association between the appearance of tumours and RCVS (Mathis et al., 2017; Arenas-Beltrán et al., 2019). Paragangliomas are the most frequent association that has been reported (Arenas-Beltrán et al., 2019). Although there is a clear physiopathological association between tumours producing vasoactive agents, the most frequently reported cases are of nonsecretory tumours ass less than $5 \%$ of the paragangliomas secrete catecholamines (Mathis et al., 2017) paraganglioma may affect the carotid body (carotid body 
tumour. As sixty percent of head and neck parangangliomas are carotid body tumours, situated at the bifurcation of the common carotid artery, it is accepted that they can compromise the baroreceptor reflex triggering trigger hypertension, headache and tachycardia (Mathis et al., 2017; Arenas-Beltrán et al., 2019).

By the time of the reporting of this case, there have been no cases of RCVS associated with suprarenal adenoma published. Although tumours may favour the appearance of RCVS, it has also been described that surgical and non-surgical oncologic treatment may induce vascular changes at the brain level that lead to the disease (Mathis et al., 2017; Duke et al., 2018; Katada et al., 2018). In the case of radiotherapy, particularly in brain tumours, it can lead to dynamic vascular lesions and generate pathologies such as RCVS, SMART syndrome (stroke-like migraine attacks after radiation therapy), Moya-Moya disease or even haemorrhagic cerebrovascular attack (Duke et al., 2018; Katada et al., 2018). Similarly, there is an association between treatment with chemotherapy and the appearance of vasospasm at the cerebral level, as is the case of the chemotherapy regimen with oxaliplatin and capecitabine, which has been linked as an aetiology of subsequent reversible leukoencephalopathy syndrome presented with RCVS in up to 38\% of cases (Mathis et al., 2017; Duke et al., 2018; Katada et al., 2018).

Given that RCVS is a clinical-radiological, multifactorial, low incidence and difficult to diagnose entity, there is not enough evidence to provide a precise physiopathological explanation which associates non-functional tumours with the disease, to such an extent that some authors exclude the presence of tumours in the risk factors for developing multifocal and segmental vasospasm at the cerebral level (Robert et al., 2013, de Boysson et al., 2018). Nevertheless, there are multiple published cases that relate both the presence of tumours with RCVS, so oncologic pathologies, even after receiving treatment either surgical, chemotherapy, radiotherapy or endovascular, should be considered as a risk factor to reduce the rate of underdiagnosis and identify new conditions that generate the disease (Mori et al., 2012; Robert et al., 2013; de Boysson et al., 2018).

\section{References}

Arenas-Beltrán, M. A., Ricaurte-Fajardo, A., Ocampo-Navia, M. I., Baracaldo, I., Mejía, J. A., Coral-Casas, J. (2019) Síndrome de vasoconstricción cerebral reversible secundario a un paraganglioma yugular secretor de metanefrinas. Rev. Neurol. 69, 220.

Calabrese, L. H., Dodick, D. W., Schwedt, T. J., Singhal, A. B. (2007) Narrative review: Reversible cerebral vasoconstriction syndromes. Ann. Intern. Med. 146, 34-44.

Cawood, T. J., Hunt, P. J., O’Shea, D., Cole, D., Soule, S. (2009) Recommended evaluation of adrenal incidentalomas is costly, has high false-positive rates and confers a risk of fatal cancer that is similar to the risk of the adrenal lesion becoming malignant; time for a rethink? Eur. J. Endocrinol. 161, 513-527.

Chen, S. P., Fuh, J. L., Wang, S. J., Chang, F. C., Lirng, J. F., Fang, Y. C., Shia, B. C., Wu, J. C. (2010) Magnetic resonance angiography in reversible cerebral vasoconstriction syndromes. Ann. Neurol. 67, 648-656.

Coral, J., Roa, W. L. F. (2009) Síndrome de vasoconstricción cerebral reversible con hemorragia subaracnoidea: reporte de caso. Acta Neurol. Colomb. 25, 137-143.

Pantoja-Ruiz C.; Ricaurte-Fajardo A.; Ocampo-Navia M. I.; Coral-Casas J. 
De Angelis, N., Romano, D., Battisti, C., Leonini, S., Federico, A. (2018) A case of reversible cerebral vasoconstriction syndrome and cavernous hemangioma: just a coincidence? Neurol. Sci. 39, 1989-1990.

de Boysson, H., Parienti, J. J., Mawet, J., Arquizan, C., Boulouis, G., Burcin, C., Naggara, O., Zuber, M., Touzé, E., Aouba, A., Bousser, M. G., Pagnoux, C., Ducros, A. (2018) Primary angiitis of the CNS and reversible cerebral vasoconstriction syndrome: a comparative study. Neurology 91, E1468-E1478.

Ducros, A. (2012) Reversible cerebral vasoconstriction syndrome. Lancet Neurol. 11, 906-917.

Ducros, A., Wolff, V. (2016) The typical thunderclap headache of reversible cerebral vasoconstriction syndrome and its various triggers. Headache 56, 657-673.

Ducros, A., Fiedler, U., Porcher, R., Boukobza, M., Stapf, C., Bousser, M. G. (2010) Hemorrhagic manifestations of reversible cerebral vasoconstriction syndrome: Frequency, features, and risk factors. Stroke 41, 2505-2511.

Duke, E., Ullrich, N. J. (2018) A 15-year-old girl with sudden onsent reversible neurologic symptoms after cranial irradiation for medulloblastoma. Semin. Pediatr. Neurol. 26, 124-127.

Grumbach, M. M., Biller, B. M., Braunstein, G. D., Campbell, K. K., Carney, A., Godley, P. A., Harris, E. L., Lee, J. K., Oertel, Y. C., Posner, M. C., Schlechte, J. A., Wieand, H. S. (2003) Management of the clinically inapparent adrenal mass ("incidentaloma”). Ann. Intern. Med. 138, 424-429.

Herrera, M., Grant, C., van Heerden, J., Sheedy, P., Ilstrup, D. (1991) Incidentally discovered adrenal tumors: an institutional perspective. Surgery 110, 1014-1021.

Hongliang, Z., Wang, X., Yang, Y., Wu, J. (2011) Reversible cerebral vasoconstriction syndrome and hemorrhagic events: Who precedes whom? Arch. Neurol. 68, 1614-1615.

Katada, E., Mitsui, A., Sasaki, S., Uematsu, N., Anan, C. (2018) Posterior reversible encephalopathy syndrome after a variety of combined chemotherapies containing bevacizumab for metastatic colon cancer. Intern. Med. 57, 2403-2407.

Mathis, S., Palazzo, P., Lamy, M., Ragot, S., Lapeyrie, S., Ricco, J. B., Neau, J. P. (2017) Posterior reversible encephalopathy syndrome and reversible cerebral vasoconstriction syndrome after bilateral carotid paraganglioma resection: a case report. Cephalalgia 37, 89-93.

Mori, K., Enomoto, T., Saida, T., Shiigai, M., Osada, K., Tanaka, N., Minami, M. (2012) Reversible cerebral vasoconstriction syndrome occurring after uterine artery embolization for uterine fibroids. J. Vasc. Interv. Radiol. 23, 1393-1395.

Nieman, L. K. (2010) Approach to the patient with an adrenal incidentaloma. J. Clin. Endocrinol. Metab. 95, 4106-4113.

Robert, T., Kawkabani Marchini, A., Oumarou, G., Uské, A. (2013) Reversible cerebral vasoconstriction syndrome identification of prognostic factors. Clin. Neurol. Neurosurg. 115, 2351-2357.

Sattar, A., Manousakis, M., Jensen, M. B. (2010) Systematic review of reversible cerebral vasoconstriction syndrome. Expert Rev. Cardiovasc. Ther. 8, 1417-1421.

Seby, J., Hajj-Ali, R., Min, D., Calabrese, L. H., Cerejo, R., Uchino, K. (2015) Reversible cerebral vasoconstriction syndrome: Is it more than just cerebral vasoconstriction? Cephalalgia 35, 631-534.

Yeh, Y. C., Fuh, J. L., Chen, S. P., Wang, S. J. (2010) Clinical features, imaging findings and outcomes of headache associated with sexual activity. Cephalalgia 30, 1329-1335. 